\title{
Mineral-Organic Interface on Clay Minerals: Imaging and Analytical Approaches
}

\author{
Alice Dohnalkova ${ }^{1 *}$, Sheryl Bell ${ }^{1}$, Montana Smith ${ }^{1}$, Libor Kovarik ${ }^{1}$, Mark Bowden ${ }^{1}$ and Kirsten \\ Hofmockel $^{1}$ \\ ${ }^{1 .}$ Environmental Molecular Sciences Laboratory, Pacific Northwest National Laboratory, Richland, \\ USA \\ * Corresponding author: Alice.dohnalkova@pnnl.gov
}

Soil microbes are responsible for contributing to the main components of the soil organic matter (SOM). Their micro- and nano-scale organo-mineral associations with soil minerals are the sites where complex processes including aggregate formation, microbial mineral weathering, and soil organic matter stabilization all occur in a narrow zone of biogeochemical gradients.

This study aimed at identifying the mechanisms underlying soil organic matter stabilization in clay minerals, by characterizing organic matter $(\mathrm{OM})$ association with mineral surfaces with high resolution multiscale visualization by chemical imaging and EDS mapping, to understand the mechanisms of OM formation and stabilization.

In a batch experiment, we used micrometer-sized aluminosilicate mineral illite as a representative of a clay mineral soil, placed in a mesh bag surrounded with live silt loam soil [1] (Benton County, WA), to provide natural microbial inoculation. Samples were incubated for 14 days, and after the destructive sampling, the dynamics of microbial $\mathrm{C}$ formation associated with illite were observed using a series of imaging and analyses including TEM imaging and elemental mapping by EDS.

Microbes formed biomass that associated with illite surfaces (Fig 1). Microbial extracellular polymeric substances (EPS) both at the minerals surfaces or away from them contained various amounts of nano-sized mineral fractions and also intact nano-scale minerals (Fig 1). We hypothesized these were secondary minerals formed by microbial activity such as mineral dissolution and precipitation, and we chemically analysed these organo-mineral associations.

In regards of microbial extraction of cations from illite, based on our previous study with another aluminosilicate, biotite [2], we expected $\mathrm{K}$ and Fe to be primarily extracted by microbial activity, as these elements are required for microbial sustenance. However, commonly present needle-like structures specifically associated with microbes contained $\mathrm{Ca}$ (Fig 2). It is likely that $\mathrm{Ca}$ was leached out from the surrounding soil to the illite mesh bag as a soluble cation, and nucleated / precipitated via microbial activity.

Simulating the clay environment with mesh bags containing pure illite dramatically decreased porosity, and overall altered the water holding capacity of the system, producing only negligible amounts of newly formed microbial biomass on illite. We augmented the structure of pure illite by adding an inert component of $500 \mathrm{um}$ quartz to improve porosity. After 14 days of incubation in the illite-quartz mix, we observed enhanced microbial biomass on illite surfaces, and direct microbial association on the mineral surfaces that were not observed in the illite-only experiment.

Multiscale and high resolution TEM imaging and chemical imaging by high resolution EDS revealed very low concentrations of dissolved cations and a variety of newly formed nanominerals specifically associated with microbial surfaces and microbial EPS. It provided a new perspective on newly formed minerals as a physicochemical way of SOM stabilization in clay minerals. This contributed to our understanding of the role of 
microbes in soil organic matter persistence in ecosystems, and it supports hypotheses in literature that are lacking the direct imaging of these processes [3].

\section{References:}

[1] Soil survey of Benton County area, Washington,

https://www.nrcs.usda.gov/Internet/FSE_MANUSCRIPTS/washington/WA605/0/wa605_text.pdf (accessed Jan 15, 2019).

[2] A Dohnalkova et al. Soils 1 (2017) https://doi.org/10.3390/soils1010004

[3] This research was performed at the Environmental Molecular Sciences Laboratory (EMSL), a national scientific user facility sponsored by the Department of Energy's Office of Biological and Environmental Research, located at PNNL.

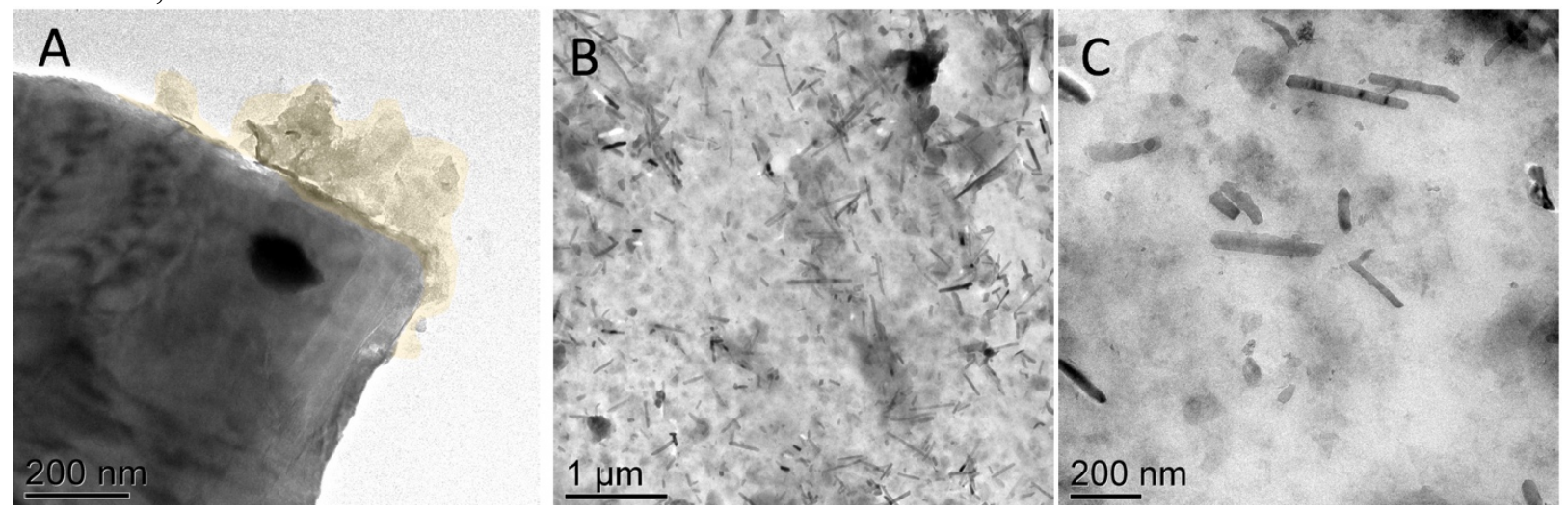

Figure 1. TEM of newly formed organic matter on an illite surface (A, color enhanced). Microbial EPS containing nanoparticulate minerals $(\mathrm{B}, \mathrm{C})$.
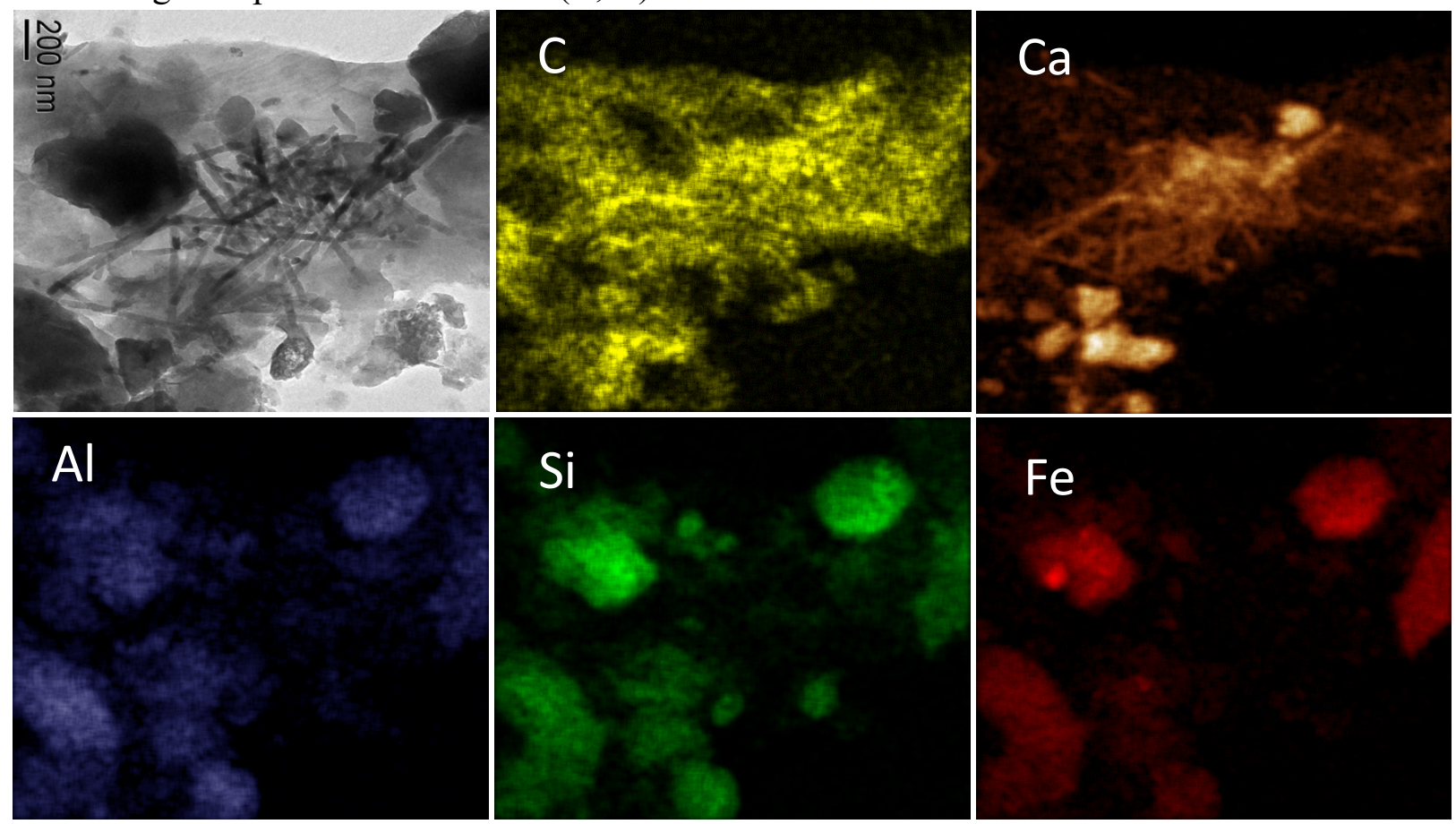

Figure 2. EDS high resolution elemental map of material intimately associated with fungal hyphae show nanocrystalline soil aluminosilicates, as well as needle-like nano-minerals, most likely formed by microbial interaction, with a specific $\mathrm{Ca}$ signal. 